\title{
INTRODUKSI PRODUK OLAHAN BERBASIS PISANG PADA UNIT USAHA PENGOLAHAN PANGAN DI DESA CILEUNYI KULON KABUPATEN BANDUNG
}

\author{
Yana Cahyana, Herlina Marta dan Dian Kurniati \\ Departemen Teknologi Industri Pertanian, Fakultas Teknologi Industri Pertanian, Universitas Padjadjaran \\ E-mail: y.cahyana@unpad.ac.id
}

\begin{abstract}
ABSTRAK. Program Pengabdian Masyarakat Dosen (PPMD) berlokasi di Desa Cileunyi Kulon Kecamatan Cileunyi Kabupaten Bandung. Khalayak sasaran yang ditargetkan adalah pemilik UKM Pengolahan Pangan dan perwakilan kader Desa Cileunyi Kulon di Kecamatan Cileunyi. Kegiatan ini bertujuan (1) Mensosialisasikan manfaat/potensi buah pisang sebagai bahan baku olahan pangan serta cara pengolahan buah pisang menjadi berbagai produk aneka camilan, (2) Mensosialisasikan cara pengemasan dan pelabelan produk pangan yang baik sehingga lebih menarik dan optimal melindungi produk sehingga dapat mengurangi produk yang dikembalikan karena rusak/return, dan (3) Membangkitkan motivasi masyarakat sasaran untuk mengembangkan pengolahan produk pangan berbasis pisang. Metode yang diterapkan pada pelatihan ini antara lain berupa penyuluhan mengenai beberapa teori yang mendukung (CPPB-IRT, potensi dan komposisi pisang, cara pengolahan pisang menjadi berbagai produk olahan pangan, cara pengemasan yang baik), praktek pengolahan pisang menjadi produk olahan pangan dan pendampingan pengolahan pisang. Output yang diinginkan dari kegiatan ini adalah antara lain: (1) Peningkatan pengetahuan dan keterampilan unit usaha sasaran mengenai potensi dan cara pengolahan buah pisang, (2) meningkatnya pengetahuan mengenai cara pengemasan dan pelabelan produk pangan yang baik, dan (3) meningkatkan motivasi untuk mengembangkan usaha pengolahan pangan berbasis pisang. Setelah kegiatan terdapat peningkatan pengetahuan dan keterampilan peserta mengenai CPPB-IRT, potensi dan komposisi pisang, cara pengolahan pisang menjadi produk pangan dan cara pengemasan dan pelabelan yang baik untuk pangan. Selain itu meningkatnya motivasi peserta untuk mengembangkan usaha di bidang produk olahan berbasis pisang.
\end{abstract}

Kata kunci: pisang; Cileunyi Kulon; produk pangan; peningkatan ekonomi

ABSTRACT. The Community Service Program (PPMD) was located in Cileunyi Kulon Village, Cileunyi Sub-District, Bandung District, West Java. The targeted audience was the owner of the Food Processing UKM and the Cileunyi Kulon Village in Cileunyi Sub-District. The purposes of this activity were (1) to socialize the benefits and potential of banana as a raw material in food products and how to process banana into various food products, (2) to socialize how to package and label food products in order to more attractive and optimal for protecting the product (3) to increase motivation of the target community to commercialize banana-based food products. The methods applied in this training and counseling on several supporting theories (good manufacturing product (GMP), potential and composition of banana, banana processing into various food products, good packaging and labelling methods) and the practice of processing banana into various food products. The targeted outputs were: (1) increasing the knowledge and skills of the target communities on the banana potential and methods to process banana into various food products, (2) increasing knowledge on packaging and labeling methods for food products, (3) improving motivation to commercialize a banana-based products. The results showed that there was an increase in participants' knowledge and skills regarding GMP, the potential and composition of banana, banana processing into food products and improve packaging and labelling for food products. In addition, there was an increase in the motivation of participants to develop businesses in banana-based products.

Key words: banana, Cileunyi Kulon, food product, economic impact

\section{PENDAHULUAN}

Perkembangan terigu sebagai bahan baku industri pangan di Indonesia kini semakin berkembang dan menjadi ketergantungan. Berdasarkan data Badan Pusat Statistik (BPS), volume impor tepung terigu Indonesia sepanjang Januari-Juni 2019 mencapai 36.467 ton, naik dari capaian periode yang sama tahun lalu sebesar 31.905 ton.Secara nilai, impor komoditas tersebut juga terekam naik, dari US\$9,95 juta pada semester I/2018 menjadi US\$12,43 juta pada semester II/2019 (Andri, 2019). Jumlah ini terus meningkat sehingga perlu dicari cara untuk mengurangi ketergantungan tersebut. Salah satunya dengan penggunaan tepung pisang kapas sebagai alternatif pengganti terigu.

Menurut Badan Pusat Statistik (2015), produksi pisang di Indonesia mengalami peningkatan dari tahun ke tahun yaitu 6,19 juta ton (2012), 6,28 juta ton (2013) dan 6.86 juta ton (2014). Jawa Barat merupakan daerah produsen pisang terbanyak ke-3 di Indonesia dengan total produksi sebesar 1.2 juta ton atau sekitar $18 \%$ dari total produksi pisang di Indonesia. Tepung pisang juga bisa dijadikan alternatif pengganti tepung terigu karena mengandung $70-80 \%$ pati berdasarkan berat kering (Zhang et al., 2005). Lebih lanjut Waliszweski et al., (2003) melaporkan bahwa pisang memiliki kandungan pati yang tinggi (70\% dari berat kering), sehingga pengolahan lanjutan menjadi tepung pisang dapat dijadikan alternative sumber daya pangan maupun untuk keperluan industri lainnya.

Kandungan gizi dalam pisang cukup baik yaitu sebagai sumber karbohidrat, vitamin dan mineral. Karbohidrat yang banyak terkandung dalam pisang adalah pati pada daging buahnya dan akan berubah menjadi monosakarida dan disakarida pada saat matang (Bello et al. 2005). Pisang pada tingkat kematangan 1 mengandung pati 70-80\% serta kadar amilosa 9-17,2\%. 
Tepung pisang mempunyai berbagai manfaat, biasanya dimanfaatkan sebagai campuran pada industri roti, biskuit dan sebagainya. Pati alami kurang cocok digunakan pada industri pengolahan pangan disebabkan sifat retrogradasi yang tinggi, serta viskositas yang tinggi (Koswara, 2006). Pati alami pisang harus dimodifikasi untuk memperbaiki karakteristiknya salah satunya dengan modifikasi fisik Heat Moisture Treatment (HMT) sehingga dapat mengubah sifat fungsional dan amilografi pati menjadi yang diinginkan seperti retrogradasi rendah, kestabilan pada suhu tinggi yang baik, dan lain-lain (Vermeylen et al. 2006 dan Pukkahuta et al. 2008).

Buah pisang secara sederhana dapat diolah menjadi makanan ringan. Masyarakat biasa meng-konsumsi buah pisang dengan cara buah pisang segar dikukus atau digoreng biasa sebagai pendamping minum teh atau kopi. Olahan buah pisang seperti ini tentu bukan merupakan olahan yang menarik dan bernilai gizi tinggi apalagi akan diusahakan sebagai usaha bisnis, selain alasan utama yaitu tidak tahan lama. Buah pisang dapat diinovasikan menjadi berbagai macam produk olahan pangan. Produk olahan pangan berbahan baku buah pisang antara lain produk aneka camilan seperti keripik pisang konvensional, keripik pisang simulasi, kecimpring, stik pisang, snack, dan lain-lain. Pisang juga bisa diolah menjadi produk setengah jadi berupa tepung dan pati dan dapat digunakan untuk menggantikan terigu dalam pembuatan berbagai produk pangan termasuk produk bakery. Kelebihan tepung pisang dibandingkan terigu adalah tepung pisang bebas gluten, dimana gluten ini merupakan allergen dan bisa menyebabkan celiac desease. Pangan fungsional yang berkembang saat ini mengarah pada pengembangan produk bakery bebas gluten (gluten free product).

Mengingat persaingan pasar di bisnis camilan sudah sangat ketat, maka diperlukan sebuah keunikan untuk meningkatkan nilai jual produk. Selain produk yang unik juga dibutuhkan pemilihan kemasan produk yang unik dan menarik, sehingga konsumen yang membeli bisa langsung tertarik untuk membelinya. Pengemasan diperlukan untuk meminimalkan atau mengendalikan proses penurunan mutu suatu produk pangan. Menurut UU no 7 tahun 1996 tentang pangan, kemasan pangan adalah bahan yang digunakan untuk mewadahi dan atau membungkus pangan baik, yang bersentuhan langsung dengan pangan maupun tidak. Menurut Saccharrow dan Griffin (1970) menggolongkan jenis dan bentuk kemasan dalam 3 golongan, yaitu : pengemasan Tegar (Rigid), pengemasan semi tegar (semi rigid), dan pengemasan lentur (flexible).

Salah satu fungsi pengemasan pangan adalah sebagai media untuk berkomunikasi dan memberikan informasi kepada konsumen. Menurut PP 69 tahun 1999 dinyatakan bahwa label pangan adalah: "Setiap keterangan mengenai bahan pangan berbentuk gambar, tulisan, kombinasi keduanya, atau bentuk lain yang disertakan pada pangan, dimasukkan, ditempelkan pada, atau merupakan bagian kemasan pangan". Untuk keperluan informasi kepada konsumen, syarat-syarat label haruslah (i) mudah dibaca, (ii) jelas terlihat, (iii) tidak disembunyikan, (iv) tidak mudah lepas, (v) tidak mudah luntur. Adapun keterangan yang perlu dicantumkankan pada label kemasan pangan adalah: Nama produk pangan, daftar komposisi bahan, isi bersih dan berat bersih, nama dan alamat perusahaan, negara asal, identifikasi lot, kadaluarsa, petunjuk penyimpanan, petunjuk pemakaian.

Teknologi pengolahan pisang dan pengemasan ini iintroduksikan pada masyarakat di Desa Cileunyi Kulon Kecamatan Cileunyi. Kecamatan Cileunyi merupakan salah satu kecamatan di Kabupaten Bandung. Pemilihan Desa Cileunyi Kulon karena di daerah ini banyak terdapat pengusaha aneka camilan dan bahan baku pisang yang tersedia. Tepung pisang bisa digunakanuntuk mensubstitusi tepung terigu dimana bahan baku yang digunakan terbatas pada terigu dalam pembuatan produknya. Dalam rangka mengurangi pemakaian terigu dan meningkatkan variasi produk, maka perlu diperkenalkan produk olahan pangan berbahan baku buah pisang. Diharapkan dengan bertambahnya variasi produk dapat memperluas pangsa pasar produk unit usaha tersebut dan mengembangkan hasil olahan pisang.

Beberapa produk aneka camilan yang telah diproduksi oleh unit usaha aneka camilan di Kecamatan Cileunyi masih memiliki kekurangan dalam hal pengemasan dan pelabelan, dimana teknik pengemasan yang digunakan masih sederhana yaitu menggunakan hekter dan belum diberi label. Hal ini menyebabkan perlindungan produk belum optimal dan kurang menarik konsumen, sehingga pada kegiatan ini juga akan dilakukan pelatihan mengenai cata pengemasan dan pelabelan yang baik.

Adapun tujuan dari kegiatan PPM ini adalah sbb: (1) mensosialisasikan manfaat/potensi buah pisang sebagai bahan baku olahan pangan serta cara pengolahan buah pisang menjadi berbagai produk olahan pangan, (2) memperbaiki pengemasan produk olahan pangan sehingga lebih menarik dan optimal melindungi produk sehingga dapat mengurangi produk return, dan (3) mengembangkan usaha dan meningkatkan pendapatan unit usaha sasaran.

\section{METODE}

PPM ini dilaksanakan dari April hingga Oktober 2018. Pemilihan Desa Cileunyi Kulon disebabkan karena Desa ini memiliki potensi produksi pisang dan terdapat pengusaha aneka camilan dan lokasi dekat dengan pemasaran sentra oleh-oleh Cileunyi.

Metode yang digunakan untuk mencpai tujuan kegiatan adalah melalui penyuluhan, pelatihan dan pendampingan. Adapun rincian metode yang diterapkan adalah sebagai berikut:

a. Penyelenggaraan pelatihan teori untuk meningkatkan pengetahuan para peserta Metode pembelajaran dalam pelatihan teori ini menggunakan metode ceramah dan 
demonstrasi. Metode ceramah dipilih untuk menyampaikan teori dan konsep-konsep substansi yang sangat prinsip dan penting, yang harus dikuasai oleh peserta pelatihan. Substansi tersebut berupa materi pokok yaitu berkaitan dengan pengetahuan tentang bahan, cara pengolahannya dan pengemasan serta pelabelan produk tersebut serta CPPB-IRT. Demonstrasi sangat penting keberadaanya dalam kegiatan pelatihan ini, karena dalam pelatihan suatu proses kerja akan lebih mudah diikuti oleh peserta pelatihan manakala keterampilan yang akan ditransformasikan bisa dieksplisitkan secara konkrit melalui demonstrasi.

b. Penyelenggaraan pelatihan praktek pembuatan produk aneka camilan berbahan baku buah pisang dan cara pengemasan dan pelabelan yang baik. Pada pembuatan produk aneka camilan, praktek dilakukan mulai dari cara mempersiapkan buah pisang sebagai bahan makanan meliputi penyortiran, trimming dan grading dan pengolahannya menjadi aneka produk pangan. Metode pembelajaran yang digunakan untuk kelancaran pelatihan adalah demonstrasi dan metode latihan. Metode demonstrasi diberikan agar peserta melihat prosedur praktek dengan baik dan kemudian dapat mengikuti melalui latihan. Metode latihan atau praktek ini diberikan kepada para peserta pelatihan dengan harapan peserta pelatihan akan mempunyai pengalaman langsung dengan melakukan sendiri atau mempraktekan materi pelatihan tentang prosedur atau langkah kerja dalam pembuatan aneka camilan berbahan baku buah pisang.

c. Metode Pendampingan. Metode ini dilakukan untuk memastikan bahwa mitra sasaran tetap melanjutkan dan mengembangkan produk olahan pisang. Tim pelaksana bertindak sebagai konsultan untuk konsultasi mengenai permasalahan yang terjadi selama proses produksi dan mencarikan solusinya.

Kegiatan PPM ini mengambil sasaran masyarakat Desa Cileunyi Kulon terdiri dari pemilik usaha aneka camilan, perwakilan ibu-ibu PKK, kelompok tani dan masyarakat produktif di daerah tersebut yang berjumlah sekitar 30 orang. Peserta merupakan perwakilan kelompok usaha yang memiliki kemampuan untuk mensosialisasikan kembali hasil pelatihan kepada anggota kelompok lainnya. Pemilihan kelompok usaha dilakukan oleh pihak Desa. Hal ini dikarenakan pihak Desa lebih mengetahui kader-kader yang berpotensi dan serius untuk mengikuti kegiatan tersebut.

Tahapan kegiatan antara lain sbb:

1) Kegiatan penyuluhan terdiri dari

- Pengetahuan mengenai CPPB-IRT (Cara Produksi Pangan yang Baik untuk Industri Rumah Tangga)

- Pengetahuan mengenai pisang meliputi: kandungan gizi dan potensinya

- Pengetahuan mengenai cara pengolahan pisang menjadi produk pangan
- Cara pengemasan dan pelabelan pangan yang baik

2) Kegiatan Pelatihan dan Praktek

- Pembuatan tepung dan pati pisang

- Pembuatan produk olahan berbahan baku pisang

- Lomba pembuatan produk olahan berbahan baku pisang

3) Pendampingan pengolahan dan konsultasi mengenai pembuatan produk olahan pisang

Target yang ingin dicapai dari kegiatan ini adalah antara lain:

1) Peningkatan pengetahuan dan keterampilan masyarakat sasaran mengenai potensi dan cara pengolahan buah pisang

2) Terciptanya variasi produk pangan berbahan baku buah pisang

3) Mendorong terbentuknya unit usaha produk pangan berbasis buah pisang

\section{HASIL DAN PEMBAHASAN}

Penyuluhan mengenai cara pengemasan dan pelabelan yang baik, CPPB-IRT (Cara Produksi Pangan yang Baik untuk Industri Rumah Tangga) dan Cara Pengolahan Pisang menjadi Produk Olahan Pangan

Kegiatan dilakukan di Balai Desa Cileunyi Kulon. Acara dihadiri oleh 30 orang peserta dari UKM, Ibu PKK dan kader desa. Metode yang digunakan berupa penyuluhan mengenai cara pengemasan dan pelabelan produk pangan yang baik, Produksi Pangan yang Baik untuk Industri Rumah Tangga (CPPB-IRT) dan Cara Pengolahan Pisang menjadi Produk Olahan Pangan. Diakhir acara diadakan diskusi dan tanya jawab mengenai materi yang diberikan. Selain itu juga dilakukan evaluasi untuk mengukur kemampuan peserta mengenai materi yang diberikan melalui pengisian kuesioner.

Khalayak sasaran untuk kegiatan penyuluhan adalah pemilik UKM, ibu-ibu PKK dan kader dari desa. Penyuluhan ini bertujuan untuk membuka wawasan kedua mitra mengenai materi tersebut. Pengemasan adalah suatu sistem terpadu untuk mengawetkan, melindungi, menyiapkan produk, hingga siap untuk ditransportasi dan didistribusikan ke konsumen dengan cara yang efektif, efisien, murah dan mudah. Kegiatan penyuluhan pengemasan dan pelabelan produk pangan diikuti oleh 30 peserta. Kegiatan ini bertujuan untuk meningkatkan pengetahuan peserta mengenai definisi, fungsi dan syaratsyarat kemasan dan label yang baik untuk produk pangan. Selain itu peserta juga dikenalkan pada jenis kemasan yang sesuai untuk mengemas aneka produk olahan pisang yang mereka produksi. Beberapa sampel kemasan untuk produk camilan diperlihatkan untuk meningkatkan wawasan peserta mengenai berbagai kemasan. Evaluasi dilakukan dengan menilai kuesioner yang berisikan soalsoal yang menyangkut pengemasan dan pelabelan produk pangan. Jumlah soal yang diberikan sebanyak 20 soal yang relevan dengan materi penyuluhan. Masing-masing soal 
diberi bobot 5 poin. Nilai akhir masing-masing peserta merupakan hasil total dari bobot jawaban yang benar.

Berdasarkan hasil evaluasi melalui kuesioner terdapat peningkatan pengetahuan peserta mengenai pengemasan dan pelabelan produk pangan. Peningkatan pengetahuan ini dinilai dari hasil perbandingan nilai yang diperoleh oleh peserta pada saat pre-test dan posttest. Hasil evaluasi terhadap peserta pengetahuan peserta penyuluhan terhadap materi pengemasan dan pelabelan produk pangan dapat dilihat pada Tabel 1.

Tabel 1. Hasil Evaluasi Terhadap Pengetahuan Peserta Penyuluhan Pengemasan dan Pelabelan Produk Pangan

\begin{tabular}{ccc}
\hline \multirow{2}{*}{ Kriteria Penilaian } & \multicolumn{2}{c}{ Persentase Peserta } \\
\cline { 2 - 3 } & Sebelum & Setelah Penyuluhan \\
\hline Rendah $(<60 \%)$ & $80 \%$ & - \\
Sedang $(60-80 \%)$ & $20 \%$ & $19 \%$ \\
Tinggi $(>80 \%)$ & - & $81 \%$ \\
Total & $100 \%$ & $100 \%$ \\
\hline
\end{tabular}

Dari tabel di atas dapat dilihat bahwa terjadi peningkatan pengetahuan peserta mengenai pengemasan dan pelabelan setelah diberikan penyuluhan. Sebelum penyuluhan, sebanyak $80 \%$ peserta memiliki tingkat pengetahuan di bawah $60 \%$ dan $20 \%$ peserta memiliki tingkat pengetahuan sedang (60-80\%). Sementara setelah penyuluhan, sebanyak $19 \%$ peserta memiliki tingkat pengetahuan sedang $(60-80 \%)$ dan sebanyak $81 \%$ peserta memiliki tingkat pengetahuan di atas $80 \%$ mengenai pengemasan dan pelabelan pangan. Setelah diberi penyuluhan, tidak ada peserta yang memiliki pengetahuan yang rendah (di bawah 60\%) tentang pengemasan dan pelabelan pangan.

Cara produksi pangan yang baik (CPPB) merupakan salah satu faktor yang penting untuk memenuhi standar mutu atau persyaratan yang ditetapkan untuk pangan, potensi dan cara pengolahan pisang menjadi produk olahan pangan. Perkembangan teknologi dewasa ini mengakibatkan perubahan dalam kebiasaan makan, yang mempunyai dampak dalam perkembangan teknik produksi dan distribusi pangan. Oleh karena itu pengawasan dalam cara produksi pangan secara efektif merupakan hal yang penting untuk mencegah gangguan kesehatan manusia dan dampak ekonomi sebagai akibat dari penyakit yang ditimbulkan oleh pangan.

Dengan demikian harus ditekankan disini bahwa pedoman produksi yang baik harus mencakup seluruh rantai pangan, mulai dari produksi primer sampai konsumen akhir.Untuk aspek pengolahan telah tersedia CPPB-IRT yang merupakan pedoman Cara Produksi Pangan yang Baik untuk Industri Rumah Tangga. Oleh karena itu dalam acara ini ditekankan beberapa pedoman aspek hulu dan hilir yang harus diperhatikan agar keseluruhan rantai pangan dapat dikontrol dengan baik.

Penyuluhan mengenai cara pengolahan pisang dimulai dari materi mengenai potensi pisang, komposisi gizi, cara pembuatan tepung dan pati pisang, serta alternatif produk yang dapat dibuat berbahan baku pisang. Beberapa produk yang dapat dibuat dari tepung pisang antara lain: cake,cookies, brownies, roti, dan lain-lain. Praktek pembuatan produk berbahan baku pisang dilaksanakan pada pertemuan selanjutnya.

Acara penyuluhan dilakukan dengan metode ceramah dan diskusi/tanya jawab. Pada sesi diskusi, masih banyak permasalahan di lapangan yang dihadapi oleh peserta untuk menerapkan CPPB-IRT, seperti lokasi produksi yang belummemadai, ketersediaan air bersih dan pengelolaan limbah yang masih terbatas. Pada akhir kegiatan dilakukan evaluasi kepada peserta untuk melihat peningkatan pengetahuan peserta terhadap materi yang diberikan. Foto-foto kegiatan penyuluhan dapat dilihat pada Gambar 1. Hasil evaluasi peningkatan pengetahuan peserta terhadap materi penyuluhan dapat dilihat pada Tabel 2.

Tabel 2. Hasil Evaluasi Peserta terhadap materi CPPB-IRT\

\begin{tabular}{lcc}
\hline \multirow{2}{*}{ Kriteria Penilaian } & \multicolumn{2}{c}{ Persentase Peserta } \\
\cline { 2 - 3 } & $\begin{array}{c}\text { Sebelum } \\
\text { Penyuluhan }\end{array}$ & $\begin{array}{c}\text { Setelah } \\
\text { Penyuluhan }\end{array}$ \\
\hline Rendah $(<60 \%)$ & $100 \%$ & - \\
Sedang $(60-80 \%)$ & & $29 \%$ \\
Tinggi $(>80 \%)$ & & $71 \%$ \\
Total & & $100 \%$ \\
\hline
\end{tabular}

Pada tabel di atas dapat dilihat terjadi peningkatan pengetahuan peserta tentang CPPB-IRT dimana sebelum pelatihan semua peserta $(100 \%)$ memiliki tingkat pengetahuan yang rendah mengenai CPPB-IRT dimana nilai isian kuesioner di bawah 60\%. Sementara setelah mendapatkan penyuluhan CPPB-IRT, sebanyak $29 \%$ peserta mendapatkan nilai $60-80 \%$ dan sebanyak $71 \%$ peserta mendapatkan nilai di atas $80 \%$. Diharapkan dengan adanya pengetahuan mengenai CPPB-IRT ini mendorong kedua mitra untuk menerapkan CPPB-IRT ini dalam proses pengolahan produknya. Sementara hasil evaluasi peserta terhadap materi pemanfaatan pisang dapat dilihat pada Tabel 3.

Tabel3. Hasil Evaluasi Peserta terhadapMateri Pemanfaatan Pisang

\begin{tabular}{lll}
\hline \multirow{2}{*}{ Kriteria Penilaian } & \multicolumn{2}{c}{ Persentase Peserta } \\
\cline { 2 - 3 } & \multicolumn{1}{c}{$\begin{array}{c}\text { Sebelum } \\
\text { Penyuluhan }\end{array}$} & $\begin{array}{c}\text { Setelah } \\
\text { Penyuluhan }\end{array}$ \\
\hline Rendah $(<60 \%)$ & $88 \%$ & - \\
Sedang $(60-$ & $12 \%$ & $20 \%$ \\
$80 \%)$ & \\
Tinggi $(>80 \%)$ & $80 \%$ \\
Total & $100 \%$ \\
\hline
\end{tabular}

Pada tabel di atas dapat dilihat terjadi peningkatan pengetahuan peserta tentang materi pemanfaatn pisang dimana sebelum pelatihan sebanyak $88 \%$ peserta memiliki tingkat pengetahuan yang rendah $(<60 \%)$ berdasarkan nilai dari pengisian kuesioner. Sementara setelah mendapatkan penyuluhan, sebanyak $20 \%$ peserta mendapatkan nilai 60 - 
$80 \%$ dan sebanyak $80 \%$ peserta mendapatkan nilai di atas $80 \%$.

\section{Pelatihan/Praktek Pembuatan ProdukAneka Camilan Berbahan Baku Buah Pisang}

Kegiatan sosialisasi dan pelatihan pemanfaatan buah pisang menjadi produk olahan pangan berhasil dilaksanakan dengan baik. Indikator keberhasilan dapat dilihat dari data pada Tabel 4 dan 5, dimana terdapat peningkatan keterampilan peserta dalam pengolahan pisang. Peserta kegiatan adalah peserta yang sama dengan kegiatan-kegiatan sebelumnya. Kegiatan ini dimulai dengan penjelasan singkat mengenai cara pembuatan produk olahan pisang seperti brownies, cake, bolu kukus, stik dan keripik pisang, kemudian dilanjutkan dengan praktek langsung pembuatan aneka produk tersebut.

Untuk menambah semangat dan motivasi peserta, kegiatan tersebut dilombakan. Peserta dibagi menjadi 4 kelompok kecil dimana per kelompoknya berjumlah 5 orang. Masing-masing kelompok bebas berkreasi untuk membuat aneka produk berbasis pisang. Kriteria penilaian meliputi ide inovasi, formulasi produk, penyiapan bahan, proses pengolahan, dan kualitas produk yang dihasilkan.

Sebelum hari pelaksanaan lomba, masing-masing kelompok sudah diminta merancang jenis produk, formulasi serta cara pembuatan produk yang akan mereka lombakan. Syarat utama dari jenis produk yang akan dibuat adalah bahan baku utama yang digunakan adalah buah pisang, baik dalam bentuk buah segar maupun pati ataupun tepung pisang. Sebelum lomba dimulai, peserta terlebih dahulu diberikan pengarahan awal mengenai peraturan dan tata tertib lomba. Waktu yang disediakan mulai dari persiapan bahan dan penyajian produk adalah selama 2 jam. Produk yang dihasilkan akan dinilai oleh juri yang terdiri dari tim pelaksana dan wakil dari Desa Cileunyi Kulon. Pada saat pelatihan juga diberikan hibah alat kepada tim PKK berupa alat pengolahan pangan seperti sealer, blender, mixer dan peralatan pengolahan lainnya.

Berdasarkan hasil lomba, beberapa produk yang dihasilkan memiliki karakteristik organoleptik yang kurang memuaskan. Karakteristik organoleptik yaitu karakteristik sensori yang mempengaruhi penerimaan produk oleh konsumen meliputi: rasa, aroma, tekstur dan penampakan keseluruhan dari produk. Produk yang dihasilkan memiliki kelemahan dari segi sifat organoletik melalui uji kesukaan panelis. Pada pembuatan cake dan bolu, tekstur yang dihasilkan kurang empuk dan agak bantat serta aroma yang dihasilkan kurang disukai. Namun ada beberapa produk yang sudah memiliki karakteristik organolepti yang memuaskan seperti cookies dan stik kering pisang seperti produk kentang kering (mustofa), namun berbahan baku pisang. Jenis pisang yang digunakan adalah pisang varietas Tanduk.

Evaluasi pelatihan praktek dilakukan untuk mengetahui kemampuan peserta dalam pengolahan pisang.
Evaluasi dilakukan pada saat proses atau praktek membuat brownies, cake dan bolu kukus, stik kering, cookies. Peserta diamati dengan lembar pengamatan yang terdiri dari 3 kriteria, yaitu: persiapan, proses pengolahan dan hasil. Hasil evaluasi terhadap keterampilan peserta pelatihan dapat dilihat pada Tabel 4. Evaluasi sikap peserta terhadap kegiatan pelatihan pemanfaatan dan diversifikasi olahan pisang menjadi produk aneka camilan dapat dilihat pada Tabel 5 .

Tabel 4. Hasil Evaluasi Terhadap Keterampilan Peserta Pelatihan

\begin{tabular}{lccc}
\hline \multirow{2}{*}{ Kriteria } & \multicolumn{3}{c}{ Persentase Peserta } \\
\cline { 2 - 4 } & $\begin{array}{c}\text { Persiapan } \\
\text { Bahan }\end{array}$ & $\begin{array}{c}\text { Proses } \\
\text { Pengolahan }\end{array}$ & $\begin{array}{c}\text { Display } \\
\text { Produk }\end{array}$ \\
\hline Rendah $(<60 \%)$ & - & - & - \\
Sedang $(60-80 \%)$ & $18 \%$ & $30 \%$ & $50 \%$ \\
Tinggi $(>80 \%)$ & $82 \%$ & $70 \%$ & $50 \%$ \\
Total & $100 \%$ & $100 \%$ & $100 \%$ \\
\hline
\end{tabular}

Tabel 5. Hasil Evaluasi Sikap Peserta terhadap Kegiatan

\begin{tabular}{lc}
\hline \multicolumn{1}{c}{ Kriteria } & Persentase Peserta \\
\hline Kurang bermanfaat & - \\
Bermanfaat & $10 \%$ \\
Sangat bermanfaat & $90 \%$ \\
Total & $100 \%$ \\
\hline
\end{tabular}

\section{SIMPULAN}

Kegiatan penyuluhan dan pelatihan pengolahan pisang memberikandampak positifbagimasyarakatDesa Cileunyi Kulon Kecamatan Cileunyi Kabupaten Bandung. Terjadi peningkatan pengetahuan dan keterampilan masyarakat mengenai pemanfaatan buah pisang sebagai produk olahan pangan, CPPB-IRT, pengemasan dan pelabelan pangan serta adanya motivasi untuk mengembangkan usaha pengolahan pangan berbasis pisang.

\section{UCAPAN TERIMA KASIH}

Ucapan terima kasih disampaikan kepada Universitas Padjadjaran yang telah mendanai kegiatan ini melalui hibah internal PPMD UNPAD.

\section{DAFTAR PUSTAKA}

Badan Pusat Statistik. 2015. Produksi Tanaman BuahBuahan Pisang (Ton). Diakses melalui www.bps. go.id.

Bello-Perez, L.A. De Fransisco, A., Agama-Acevedo, E., Gutierrez-Meraz, F., and Garcia-Suarez, F.J.L. 2005. Morphological and Molecular Studies of Banana Starches. Food SciTech Int. 11: 367-372.

Koswara, S. 2006. Pisang sebagai Cadangan Pangan Alternatif. Ebookpangan.com. 
Pukkahuta, C.; Suwannawat, B.; Shobsngob, S.; Varavinit, S., 2008 Comparative study of pasting and thermal transition characteristics of osmotic pressure and heat-moisture treated corn starch. Carbohydr. Polym. 72 (3), 527-536.

Saccharrow, S. and R.C.Griffin. 1970. Food Packaging, The AVI Publishing Company, Westport, Connecticut.

Vermeylen, R.; Goderis, B.; Delcour, J. A., 2006 An x-ray study of hydrothermally treated potato starch. Carbohydr. Polym. 64 (2), 364-375.
Walizewski, K. N., Mario, A. A., Luis A. B., Jose, A. M. 2003. Changes of banana starch by chemical and physical modification. Carbohydr. Polym. 52:237342.

Andri, Y.D.P. 2019. Konsumsi Melambat, Impor Terigu Semester I/2019 Justru Melonjak. Available at: https:/ekonomi.bisnis.com/read/20190722/12/ 1127058/konsumsi-melambat-impor-terigusemester-i2019-justru-melonjak. Diakses tanggal 1 Januari 2019.

Zhang, P.; Whistler, R. L.; BeMiller, J. N.; Hamaker, B. R., 2005 Banana starch: Production, physicochemical properties, and digestibility-a review. Carbohydr. Polym. 59 (4), 443-458. 